\title{
Mechanism of MicroRNA-146a/Notch2 Signaling Regulating IL-6 in Graves Ophthalmopathy
}

\author{
Ning Wang ${ }^{a}$ Feng-E Chen ${ }^{a}$ Zi-Wen Long ${ }^{b, c, d}$ \\ aShanghai General Hospital, Department of Ophthalmology, Shanghai Jiao To \\ of Medicine, Shanghai, bepartment of Gastric Cancer Surgery, Fur 'Iniversity \\ Center, Shanghai, 'Department of Oncology, Shanghai Medical C \\ ${ }^{\mathrm{d}}$ Department of Medicine, Shigatse People's Hospital, Shigatse, P.

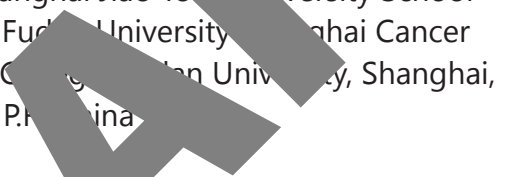 \\ Key Words \\ Graves ophthalmopathy $\cdot$ Notch2 $\cdot$ MicroRNA-1 \\ IL-6 • qRT-PCR • Orbital Fibroblast \\ reporter gene
}

Abstract
Background/Aims: We intended to i
and IL-6 on Graves ophthalmopathy About $27 \mathrm{GO}$ patients were ir and14 patients with active $G$ orthopedics or ophthalmer ning PCR assay was used to $C^{\prime}$ assay and flow cytomet fibroblasts isolated from ct mici study, including 13 patients with inactive GO 2 thic significance of microRNA-146a, Notch2 ar an the relationships among them. Methods: ther _._. atients who had previously received strabismus auma were selected as the control population. QRTvere mspectively used to assess the viability and mitosis of the inective tissue. Double antibody sandwich enzyme-linked immunosorbent Lis,n, was employed to detect serum IL-6 levels. The dual luciferase reporter gene se sed to verify the targeting relationship between microRNA-146a and Notch Res s: mpared with the control group, the relative expression of miR146a wa nific icreased whereas the relative expression of Notch2 was significantly decreas $\quad P<0.05$ ) in GO patients compare with the control. Notch2 can be directly d b, roRNA-146a. The over-expression of miR-146a markedly facilitated Orbital asts $(0,0)$ viability and mitosis whereas markedly suppressed cell apoptosis (all $P<$ 0.05 , Jous microRNA-146a mimics could down-regulat the expression of Notch2 and regurue IL-6 $(P<0.05)$. The inhibition of microRNA-146 resulted in the elevated expression Mtch2 and decreased expression of $I L-6(P<0.05)$. Conclusion: MicroRNA-146a may ir ase the IL-6 levels and exacerbate GO by directly targeting Notch2.

\section{Introduction}

Graves ophthalmopathy (G0) is a relatively common autoimmune disease that is closely associated with hyperthyroidism due to Graves' disease, the exact etiology and underlying

Ziwen Long

and Feng-E Chen

\section{KARGER}

Department of Gastric Cancer Surgery, Fudan University Shanghai Cancer Center, Building 3, No. 270, Dongan Road, Xuhui District, Shanghai 200032, (P.R. China); Shanghai General Hospital, Department of Ophthalmology, Shanghai Jiao Tong University School of Medicine, No. 100 Haining Road, Hongkou District, Shanghai 200080, (P.R. China) E-Mail baerriza82@163.com / fenge_chen@126.com 


\section{Cellular Physiology and Biochemistry}

mechanism of which still remain to be clarified [1]. GO is characterized by inflammation of the extraocular muscles and orbital connective tissues, which is caused by the infiltration of lymphocytes and macrophages [2,3]. The infiltrated lymphocytes and macrophages generate cytokines and lead to the tissue inflammation [4]. The inflammation process involves a spectrum of chemokines and cytokines such as $I L-6$. Orbital fibroblasts are particular susceptible to many pro-inflammatory cytokine activities. The intense immune response are believed to account for the manifestation of Grave's disease [4]. Therefore, a thorough understanding of the involved cells, the cytokines, and the nature of their interplay is crit' to manage GO [5].

$I L-6$ has been found to be closely correlated with GO pathogenesis, which istim the thyroid stimulating hormone receptor (TSH-R) expression and increase the nto in the orbital fat tissue differentiation process of patients [6, 7]. The regu ir of nay present as a novel management method for GO.

Accumulating evidence shows that microRNAs (miRNAs), a class RNAs, have significant negative modulating effects in pathological and phy of various autoimmune diseases [8]. MiR-146a, a member of the cla. found to participate in the pathogenesis of autoimmune dis roch as natoid arthritis (RA), Osteoarthritis (OA), systemic lupus erythematosus cosis (MS) and GO [3, 9-13]. For instance, MiR-146a was reported to indu cNe ction by targeting TNF- $\alpha$ /TNF receptor-associated factor 6 (TRAF6)/IL-1 recep ocmed kinase 1 (IRAK1) signaling in RA [14]. Again, miR-146a was re ted to dow gulate IL-6 production in orbital fibroblasts [15]. Besides, the overexpres of miR-14 could be induced by IL-10 and TGF- $\beta$ but reduced by IL- 12 and IFN $\alpha / \beta$ in b suppression of NK cell-mediated cytotoxicity IFN F $\alpha$ production [16].

He et al. demonstrated that miR-146a is a tive alatory factor of LPS-induced IL-6 production by targeting Notch1 in LPS-i $\mathrm{i}$ - 4 macrophage cells [17]. MiR-146a could also regulate Notch1 to modul it phage polarization, which could potentially regulate inflammatory diseases [18]. $\quad$ /Notch signaling promoted Fc epsilon RImediated IL-4, IL-6, IL-13 a of bone marrow-derived mast cells, which contributed to the differentia $\quad{ }^{C} \mathrm{CD} 4(-\mathrm{r})$ cells into T (H) 2 [19]. Intriguingly, it was found that the overexpression of tive Notch1 and Notch2 suppressed the production of TLR4-triggered pro-infl natory _, kines such as IL-6 and TNF $\alpha$ in macrophages [20]. However, the involveme Not $^{\wedge} 2$ in the autoimmune thyroiditis has not been clarified.

Notch2 is a putative miR-146a, and considering the close relationship between miR-146a or No ling and GO or IL-6, we believe that the occurrence and development of GO is likely relationsh bet n miR-146a/ Notch2/ IL-6 pathway and the development of GO. Howeve beli eir interplay could play a significant role during GO pathogenesis. Therfor designed this study to clarify the role of microRNA-146a/ Notch2/ IL-6 ing in development of GO and helped with the understanding of the pathogenesis

vhich ould provide a new intervention strategy for the prevention and treatment of

\section{( \\ Material and Methods}

\section{Research Subjects}

Samples were obtained from the twenty-seven GO patients who accepted surgical treatments in Shanghai General Hospital from August 2014 to October 2014. The baseline characteristics of the objects were shown in Table 1. Patients with strabismus orthopedics or ophthalmectomy due to trauma were selected as the control group with similar age and gender ratios to their counterparts (the patients with GO). All of the patients with other autoimmune diseases were excluded. Ethics Committee of Shanghai General Hospital approved our research, and all the patients signed the consent forms.

\section{KARGER}




\section{Cellular Physiology Cell Physiol Biochem 2017;41:1285-1297 \begin{tabular}{c|c|c|c|} 
DOI: 10.1159/000464430 & C 2017 The Author(s). Published by S. Karger AG, Basel \\
www.karger.com/cpb
\end{tabular}

Table 1. Demographic and clinical characteristics of patients. FT3: serum free triiodothyronine; FT4: serum free thyroxine; CAS: clinical activity score; ${ }^{a}$ applies one-way ANOVA, ${ }^{b}$ applies Chi-square test, ${ }^{\mathrm{c}}$ applies t-test

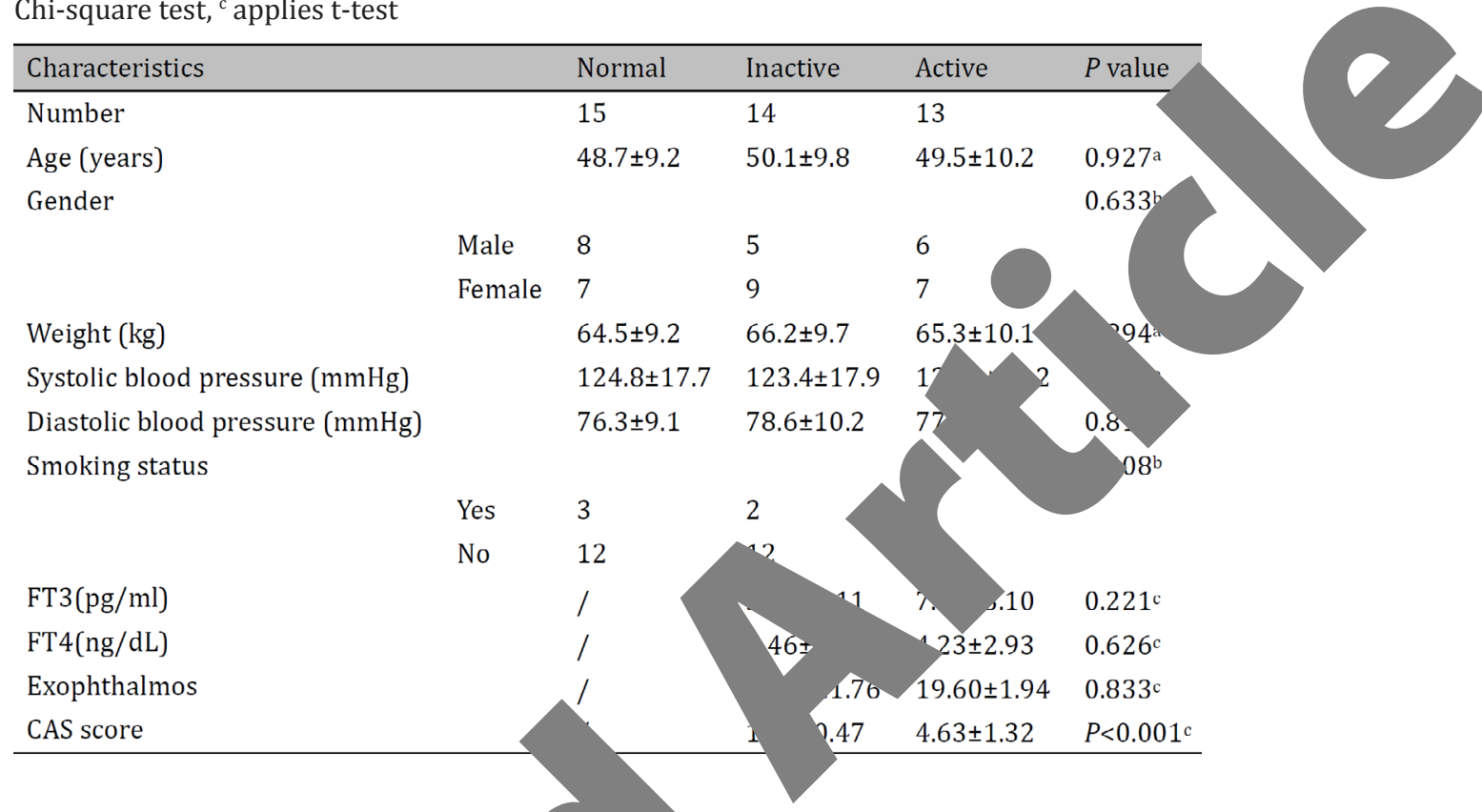

Orbital fibroblasts (OFs) separation and cultiva (FACS)

The orbital connective tissue of GO patients at sterile condition, and thereafter were placed in $0^{\circ} \mathrm{C}$ ice water mixture, and transferred to in 5 hours. The samples were pla $\mathrm{d} / \mathrm{Pe}$ by PBS (Phosphate Buffered Salin larger vessels were removed. Th plastic pipette, and they wer and Fluorescence Activated Cell Sorting containing $20 \%$ fetal calf se flipped and put in a carbon a the tissue was attar culture media wf alf

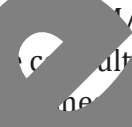
rol group patients were removed under dium immediately. The cell culture was put
re laboratory. The experiment was then conducted rre laboratory. The experiment was then conducted
the laminar flow bench, and washed three times en thu were cut into pieces after the adipose tissue and We then sucked into $25 \mathrm{ml}$ cell culture flasks using a sterile dributed on the sidewall. Thereafter the DME/ F12 medium was added into the flasks. Lastly, the caps were covered, the flasks were ator with $5 \% \mathrm{CO}_{2}$ and $95 \%$ humidity at $37^{\circ} \mathrm{C}$. After $2-4$ hours when e s. the flasks were flipped and set flat for static culture. Thenceforth, the ry two to three days. Within 3-5 days, new cells were seen growing from the tissue. The $c^{-11}$ morp og Aerence rate and proliferation rate were consistently recorded.

When cells 5 cover about $90 \%$ of the culture bottle wall within 7-10 days, the media were drained. Ilture was then washed twice with PBS and digested by $0.25 \%$ trypsin. Then the separated re $p$ into single cell suspension in DMEM/F12 cell culture medium containing $10 \%$ fetal calf
and sub cured. nd sub cured. were examined for fibroblast markers using immunostaining as well as FACS (FACSCalibur,

Bios es, NJ, USA). The cells that are morphologically consistent with a fibroblast phenotype, i.e. they monstrated positive staining of vimentin, collagen and fibroblast antigen but negative staining of desmin ar yosin [21-24]. The flow cytometer was also employed do ensure the cell purity ( $>90 \%$ pure).

\section{Immunofluorescence assay}

Well-grown cells were selected. After cells passed on to the third generation, the cells in logarithmic growth phase were selected and seeded in a 6-well plate covered with pre-sterilized coverslips. When cells grew to $70 \%$, all the cells were washed with PBS 3 times. Then air-dried and fixed in situ for 30min with $4 \%$ formaldehyde (the volume fraction), all the cells were washed with PBS. Cells were permeabilized with PBS containing $0.2 \%$ Triton X-100 for 20 min at room temperature. Mouse anti-human vimentin, desmin, S-100, and keratin cytokeratin monoclonal antibody (1:100 dilution) were added to the well, respectively. Cells were washed 3 times in cold PBS, incubated for $1 \mathrm{~h}$ at room temperature with Alexa Fluor F(ab')2

\section{KARGER}




\section{Cellular Physiology Cell Physiol Biochem 2017;41:1285-1297 \begin{tabular}{c|c|c|} 
DOI: 10.1159/000464430 & Ond Biochemistry 2017 The Author(s). Published by S. Karger AG, Basel \\
wwww.karger.com/cpb
\end{tabular} and Biochen/Long: MicroRNA-146a Regulates IL-6 in Graves Ophthalmopathy via Notch2}

Table 2. Primer sequence of microRNA-146a and U6. *F: Forward, R: Rever

\begin{tabular}{|c|c|c|}
\hline & & Primer sequence \\
\hline \multirow{2}{*}{ miR-146a } & $\mathrm{F}$ & 5'-CACTCCAGCTGGGTGAGAACCTCAACTGGTGTCGTGGA-3' \\
\hline & $\mathrm{R}$ & 5'-CTCAACTGGTGTCGTGGAGTCGGCAATTCAGTTGAGAACC \\
\hline \multirow{2}{*}{ Notch2 } & $\mathrm{F}$ & 5'-CCAGCATGGCCAGCTCTGG-3' \\
\hline & $\mathrm{R}$ & 5'-CATCCAGATCTGTGGCCCTGTT-3' \\
\hline \multirow{2}{*}{ U6 } & $\mathrm{F}$ & 5'-CTCGCTTCGGCAGCACA-3' \\
\hline & $\mathrm{R}$ & 5'-AACGCTTCACGAATTTGCGT-3' \\
\hline \multirow{2}{*}{ GAPDH } & $\mathrm{F}$ & 5'-GTGGACCTGACCTGCGTCT-3' \\
\hline & $\mathrm{R}$ & 5'-GGAGGAGTGGGTGTCGCTGT-3' \\
\hline
\end{tabular}

fragment of goat anti-mouse IgG (Invitrogen, CA). After washing, cells were incubatea min in amidino-2-phenyl indole (DAPI) to visualize nuclei, washed again in PBS and moun a d a tion by fluorescence microscopy in a Carl Zeiss Axioplan 2 immunofluorescence microscone ctures cquired using Axiovision V4 software. The positive staining of Vimentin and negative stan fother proteins were identified as orbital fibroblasts.

\section{Real-time fluorescent quantitative PCR}

Total RNA was extracted from sample tissues using the Trizol $\mathrm{m}$ instructions (Invitrogen, Carlsbad, CA, USA) and th ntical densit s measured to perform RNA quantitative analysis. PCR was applied for the reverse viption of R emplates, Applied Biosystems 7500 Fast Real-Time PCR System (ABI7500 quantitat- Applied Biosystems, Waltham, MA, USA) was used for Real-time quantitative RT-PCR experi its. TT-PCR reaction conditions were predenaturation at $95^{\circ} \mathrm{C}(10 \mathrm{~min})$, denaturation at $95^{\circ} \mathrm{C}$ ann $\mathrm{g}$ at $60^{\circ} \mathrm{C}(20 \mathrm{~s}, 40 \mathrm{cycles})$, extension at $72^{\circ} \mathrm{C}(34 \mathrm{~s})$. The primer senuences were show $\mathrm{dd} \mathrm{GAPDH}$ were the reference controls for miRNA and mRNA. ${ }^{-\Delta \Delta C_{t}}$ method was us at atne relative expression of miRNA or mRNA. The experiment was repeated three times.

Dual luciferase reporter gene

The OFs were seeded in $3-\mathrm{we}$

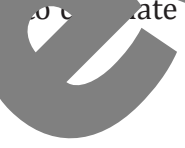
to the LipofectamineTM 200 reference plasmid pRL-CMV away, the cells were wroched ansfectio. gent instructions. $1 \mu \mathrm{l}$ Lipofectamine 2000, and $1 \mathrm{ng}$ internal adde to each well. After transfection for $48 \mathrm{~h}$, the old medium was sucked 1 PBS and $100 \mu \mathrm{L}$ PLB was added to each well. The plate was then gently shaken for as atroom temperature, and the cell lysates were collected. $100 \mu$ LARII was predisposed int ter tubes to complete the desired number of DLR assays. The luminometer was prograr ed t rf a 2-second premeasurement delay, followed by a 10-second measurement period fo repo say. Up to $20 \mu \mathrm{l}$ cell lysate was transferred to the luminometer tube containing I 'RIJana $\quad$ by pipetting 2 or 3 times. $100 \mu \mathrm{l}$ Stop \& Glo ${ }^{\circledR}$ Reagent was injected into every well. The tube in pul luminometer and the program was run by a double fluorescence detection kit (Promega, WI Us, . The data was then exported and saved.

\section{Ce. ouping and transfection}

OFs were used to conduct the experiment and they were divided into five groups: control group (cells re ed no treatment), miR-146a mimics group (cells transfected with miR-146a mimics sequence), miRoa inhibitors group (cells transfected with miR-146a inhibitor sequence), NC (miR-146a negative control duplex) group and p-Notch2 group (cells transfected with pcDNA3.1-Notch2). Transfection was performed using Lipofectamine 2000 (Invitrogen, Carlsbad, CA, USA). MiR-146a mimics, miR-146a inhibitors and Negative Control duplex products were purchased from Hai Jima biotechnology company, Shanghai.

\section{Western blot}

The cultured cells were washed 3 times using pre-cooled PBS. Subsequently, $100 \mu \mathrm{l} / 50 \mathrm{ml}$ cells were placed on ice for $30 \mathrm{~min}$. The cells were centrifuged at $12,000 \mathrm{rpm}$ for $10 \mathrm{~min}$ under $4^{\circ} \mathrm{C}$. The suspension was then collected into a $0.5 \mathrm{ml}$ centrifuge tube and stored under $-20^{\circ} \mathrm{C}$. The $2 \mu \mathrm{g} / \mu \mathrm{l}$ BSA standard protein

\section{KARGER}




\section{Cellular Physiology Cell Physiol Biochem 2017;41:1285-1297 \\ \begin{tabular}{ll|l} 
DOI: 10.1159/000464430 & O 2017 The Author(s). Published by S. Karger AG, Basel \\
www.karger.com/cpb
\end{tabular}}

Wang/Chen/Long: MicroRNA-146a Regulates IL-6 in Graves Ophthalmopathy via Notch2

solution was serially diluted with PBS to $20 \mu \mathrm{g} / \mu \mathrm{l}, 15 \mu \mathrm{g} / \mu \mathrm{l}, 10 \mu \mathrm{g} / \mu \mathrm{l}, 5 \mu \mathrm{g} / \mu \mathrm{l}, 2.5 \mu \mathrm{g} / \mu \mathrm{l}$, and $0 \mu \mathrm{g} / \mu \mathrm{l}$. The BCA kit (Pirece, Rockford, IL, USA) were diluted by 50:1. $2 \mu$ lysed protein samples were diluted with $18 \mu \mathrm{l}$ double distilled water. On a 96-well plate, $200 \mu \mathrm{l}$ testing solution was added to each of the wells as well as $10 \mu \mathrm{l}$ reference protein solution and $10 \mu \mathrm{l}$ solution ready for examination. The plate was then incubated under $37^{\circ} \mathrm{C}$ for $30 \mathrm{~min}$ and cooled down to room temperature. The OD was measured at $490 \mathrm{n}$ Protein samples were then stored under $70^{\circ} \mathrm{C}$. Electrophoresis (60V) was performed before the separatin gel electrophoresis $\left(120 \mathrm{~V}, 1-2 \mathrm{~h}\right.$ at $\left.4^{\circ} \mathrm{C}\right)$. Subsequently, the proteins were transferred from gel to a PVDF membrane (1-2 h), which was then incubated with mouse anti-human primary antibodies of Notch2 IL-6 (Shanghai SUNBIO Ltd., China) overnight at $4^{\circ} \mathrm{C}$. The next day, the membrane was washed 3 times TBST (10min every time). Then the rabbit anti-mouse secondary antibodies were added al incubated for $1 \mathrm{~h}$. The membrane was then washed with TBST three times, 10 min every time room, the X-ray film was developed and fixed. Finally, ImageJ was used to extract the in

MTT cell proliferation assay

When the density of transfected cells reached about $80 \%$, cells were washer were digested with trypsin and suspended. The number of cells was counted usi seeded into a 96-well plate with $3 \times 10^{3}-6 \times 10^{3} / 200 \mu \mathrm{l}$ volume prell. MT1

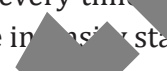
Aldrich, St. Louis, MO, USA) were placed into each well and the o $\quad \mathrm{h}$ at $37^{\circ} \mathrm{C}$ in an incubator with $5 \% \mathrm{CO}_{2}$. Subsequently, dimethyl sulfoxide (DMSO, 1 J) to each well and cells were gently shaken for about 10 minutes in order to dissolve the to detect the absorbance value of each well at a wavel th of $490 \mathrm{~nm}$ re same time for five days. The experiment was repeated for three times.

\section{Flow cytometric analysis}

$3 \times 10^{5}$ cells from each group were collected at cubà Cells were then washed with PBS three times and tre were then treated with $50 \mathrm{ug} / \mathrm{ml}$ propidiur was measured with a FACS can flow cytome V-FITC/PI Apoptosis Detection Kit'BDD Bios the samples were measured.

\section{ELISA analysis}

The expression level MN, USA) according to the measured using the USA).

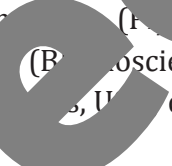
5 hour in the dark. The DNA distribution sciences, USA). The cells were stained with Annexin , $\mathrm{V}$ during flow cytometry and the apoptosis rates of

\section{Patients characteristics}

This study included 42 objects: 15 healthy individuals and 27 GO patients (14 patients with inactive GO and 13 patients with active GO). As shown in Table 1, the age, gender ratios, weight, blood pressure and smoking status of the patients in the three groups did not demonstrate a significant difference $(P>0.05)$. Among the three indexes measured of G0 patients, that is, serum free T3, T4 and exophthalmos showed no substantial difference between the inactive and active GO groups $(P>0.05)$. The difference was significant in CAS score between active and inactive GO groups $(P<0.001)$. 

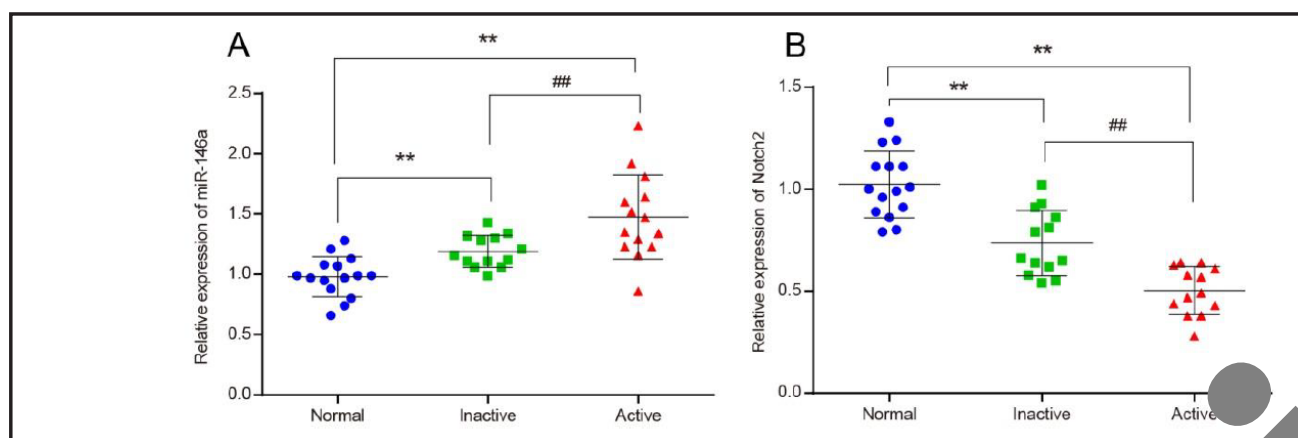

Fig. 1. The expressions of microRNA-146a and Notch2 in patients' tissues. (A) Differenc in the of miR-146a among normal tissues, active GO tissues and inactive GO tissues. (B) Diff sions of Notch2 among normal tissues, active GO tissues and inactive GO tissues. Nor normal control group, Inactive represented inactive GO group and Active represen Data were presented as mean $\pm \mathrm{SD}$. **, $P<0.01$ compared with normal group; inactive GO group. GO: Graves ophthalmopathy.
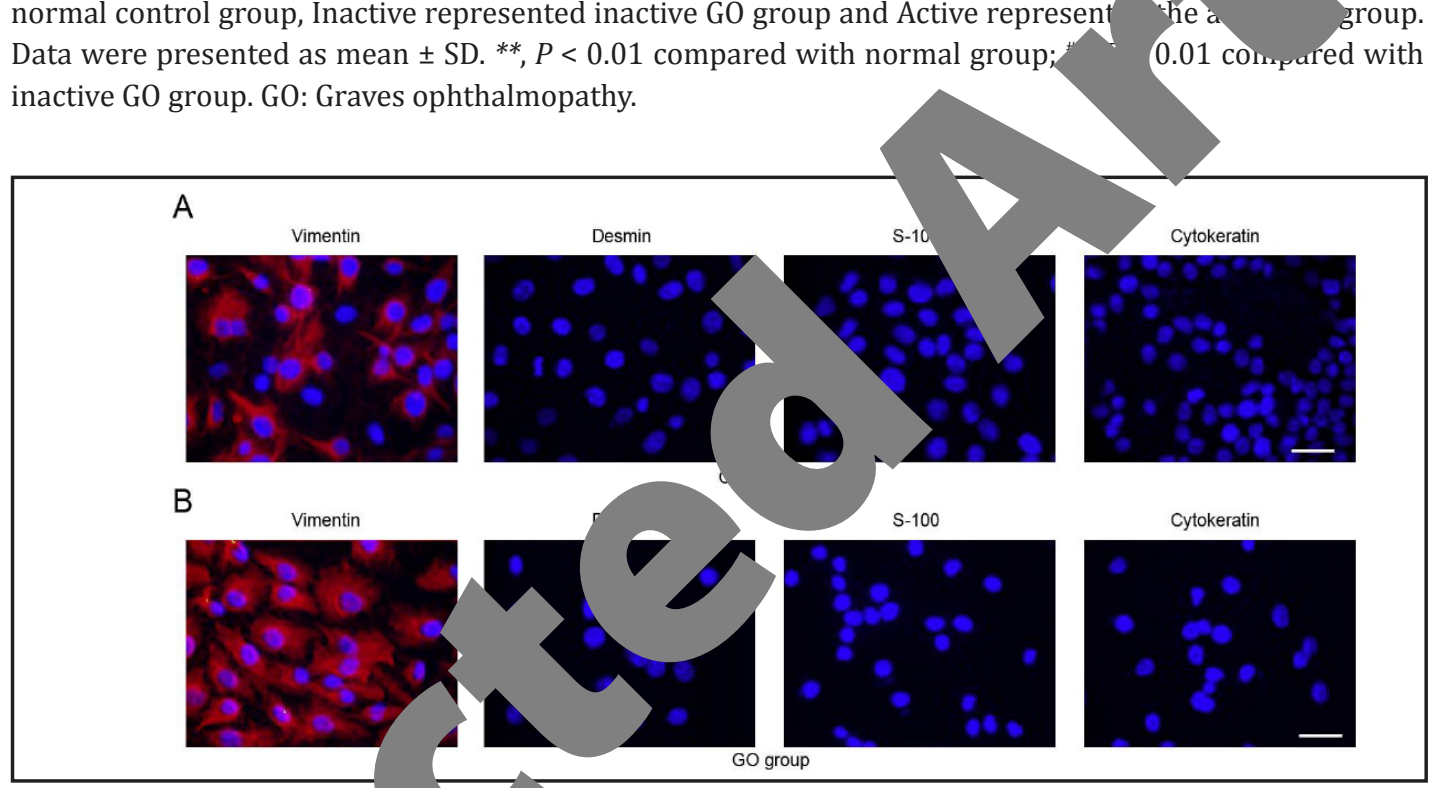

Fig. 2. Immunofluorescence s. (A) The expressions of Vimentin, Desmin, S-100 and Cytokeratin in the control grou Fluor 594 goat ar econdary antibody and DAPI staining for nucleus (1000×magnification). GO: Graves opht' 'mop?

pro

levels of miR-146a and Notch2 in GO tissues

vasses, hether the expressions of miR-146a or Notch2 was increased in the tissues, qu' s performed in 27 GO tissues samples and 15 normal tissues samples. The vres. of miR-146a in GO tissues was significantly up-regulated in comparison with

atin normal tissues, and the expression of miR-146a in the active GO group significantly er ded that in the inactive group (all $P<0.05$ ) (Fig. 1A). The expression level of Notch2 in tissues was significantly lower than that in normal tissues, and that in the active group was significantly lower than that in inactive group (all $P<0.05$ ) (Fig. 1B).

\section{Immunofluorescence assay results}

To distinguish the orbital fibroblasts, immunofluorescence assay was used in the study. As shown in Fig. 2, Vimentin expression of OFs was positive in the GO group and control group and the cytoplasm was stained in red, indicating a mesenchymal origin of the cells. Desmin expression of OFs was negative in the GO group and control group, and the nuclei were stained in blue, indicating that the origins of the cells such as the smooth muscle,

\section{KARGER}


Fig. 3. The effect of miR-146a and Notch2 on OFs viability was evaluated using MTT assay. Control represented control group (OFs received no treatment), miR-146a mimics represented miR-146a mimics group (OFs transfected with miR-146a mimics sequence), miR-146a inhibitors represented miR-146a inhibitor group (OFs transfected with miR-146a inhibitor sequence), NC represented negative control group (OFs transfected with miR-146a negative control duplex) group and p-Notch2 represented p-Notch2 group (OFs transfected with pcDNA3.1-Notch2). Data were presented as mean \pm SD. ${ }^{* *}, P<0.01$ compared with control group; ${ }^{\#}, P<0.01$ compared with the NC group; $\&$ \&, $P<0.01$ compared with the miR-146a mimics group. OFs: Orbital fibroblasts.

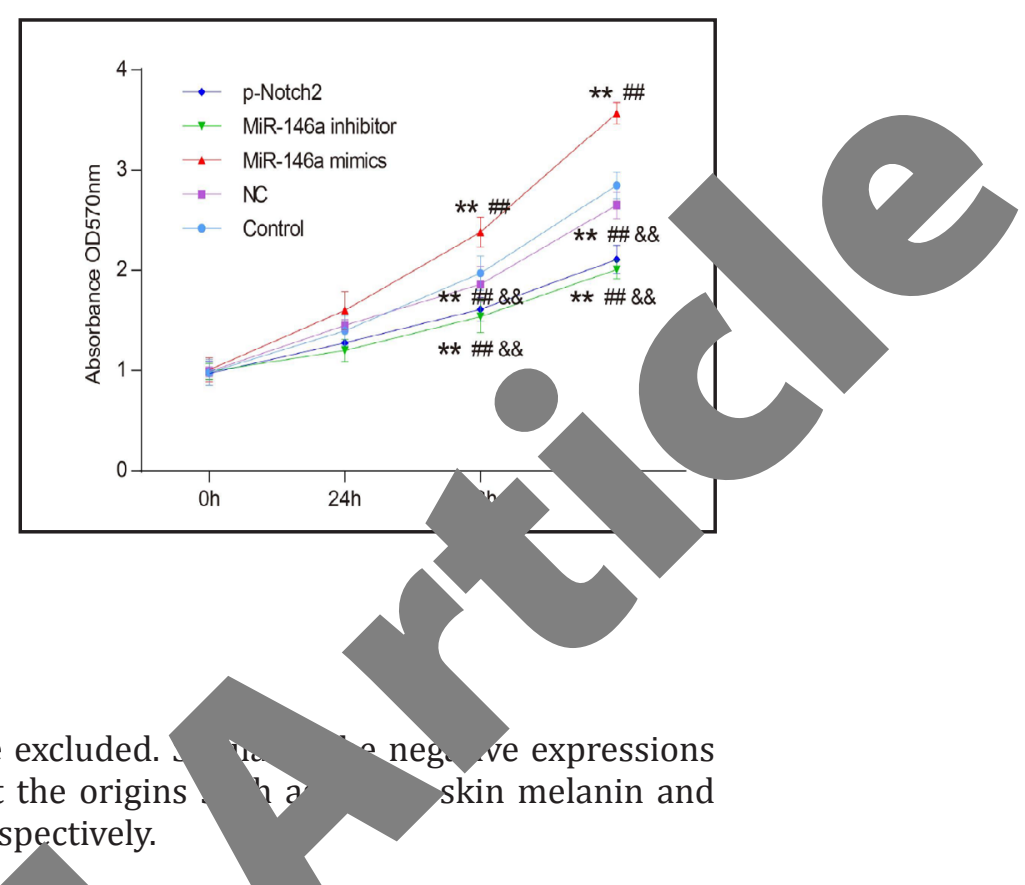

striated muscle and cardiac muscle could be excluded. of S-100 and Cytokeratin also indicated that the origins epithelium, and mesothelium are excluded respectively.

The effects of miR-146a and Notch2 on cell $p$

To determine the effects of miR-146a and was analyzed for their viability. As suggeste significant difference in cell viability betwee mimics significantly strengthened the exogenous Notch2 had the reverse eff (all $P<0.05$ ). The miR-146a inhibitor on $\mathrm{OF}$ viability $(P>0.05)$. Co 146a inhibitor and p-Notch2

\section{ration}

on proliferation in vitro, MTT assay M. say result (Fig. 3), there was no $\mathrm{N}$ and control groups. The miR-146a ereas the miR-146a inhibitors and ared with the control group or the NC group xo ous Notch2 had identical inhibitory effects $\mathrm{g}$ (iR-146a mimics group, the cells in the miRwere ress viable.

The effects of $m i R-1$ and Now on cell apoptosis and cell cycle

To assess the contr the cell apoptosis $n$ that there was $\mathrm{NC}$ groups (al, in $\mathrm{G} 0 / \mathrm{G} 1$ The ce

\section{miR-} 1 different groups. The results of flow cytometry showed e dirrerence in cell cycle and apoptosis between the control and the Yhen compared with the control group, the proportion of cells reas that in S and G2/M increased in the miR-146a mimics group. inhibitor and p-Notch2 showed similar cell cycle progression $(P>$ ' 5 i.e. vercentage of cells in G0/G1 phase increased significantly and that in S and decro compared with the control group $(P<0.05$, Fig. 4A). Comparing with miRimics group, cell cycle arrest in the miR-146a inhibitor and p-Notch2 groups were ioni enhanced.

Consistently, no significant difference was observed between the control and NC groups. 20 ared with the control group, the cells in the miR-146a mimics group demonstrated snificantly lower apoptosis rate (both $P<0.05$ ). On the contrary, the apoptosis rate of ofs was significantly higher in the miR-146a inhibitor group and p-Notch2 group compared with the control group or the NC group (both $P<0.05$ ). Meanwhile, there is no difference between the miR-146a inhibitor and the p-Notch2 groups $(P>0.05)$. Comparing with miR146a mimics group, cell apoptosis rates in the miR-146a inhibitor and $\mathrm{p}-$ Notch2 groups were substantially higher.

Dual luciferase reporter gene assay results

Dual luciferase reporter gene assay was utilized to verify the target relationship between miR-146a and Notch2. The complementary sequences of Notch2 3'UTR and miR-146a as KARGER 


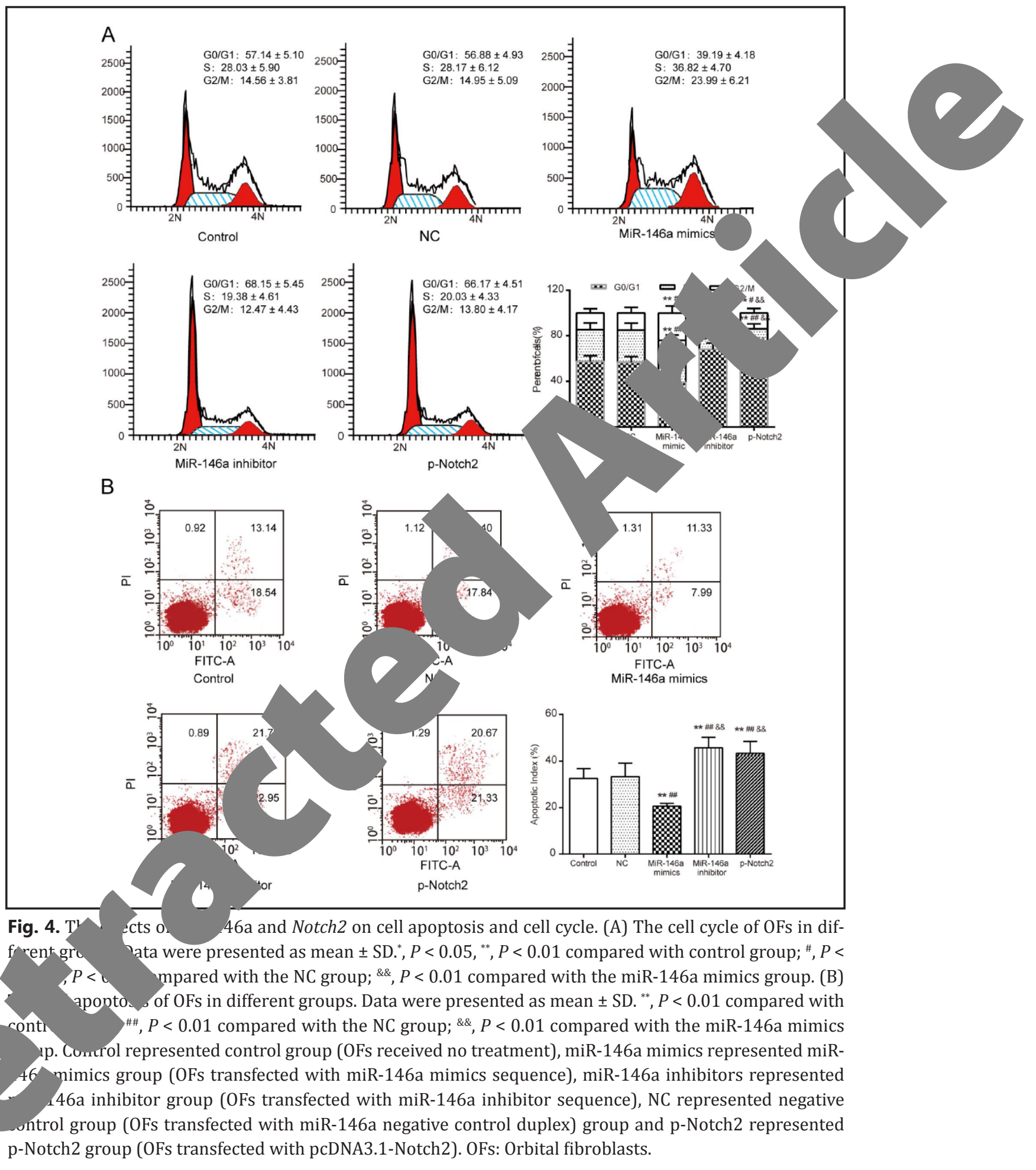

well as the mutated Notch2 3'UTR were shown in Fig. 5A. Only the co-transfection of pGL3Notch2-3'UTR-wt and miR-146a mimics weakened the fluorescence (Fig. 5B). The cells cotransfected with pGL3-Notch2-3'UTR-mut and miR-146a mimics did not show significant alteration in fluorescence compared with the NC group $(P>0.05)$. 
A

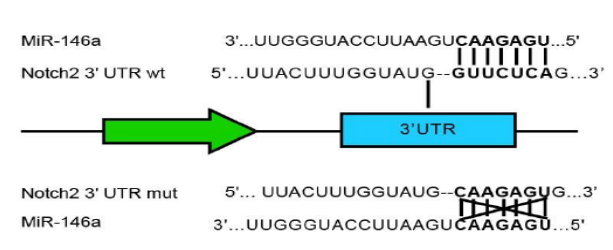

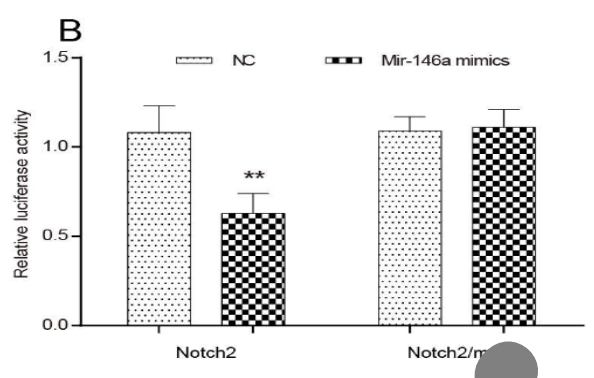

Fig. 5. Notch2 was a target of miR-146a. (A) Sequence scheme of miR-146a, Notch2 3'-UTR-wt ${ }^{\text {No }}$ 3'-UTR-mut. (B) Fluorescence measurement of cells with different transfections. NC revrecent control group (OFs transfected with miR-146a negative control duplex) group and mis sented miR-146a mimics group (OFs transfected with miR-146a mimics sequence). Da mean \pm SD. ${ }^{* *}, P<0.01$ compared with the NC group. OFs: Orbital fibroblasts.

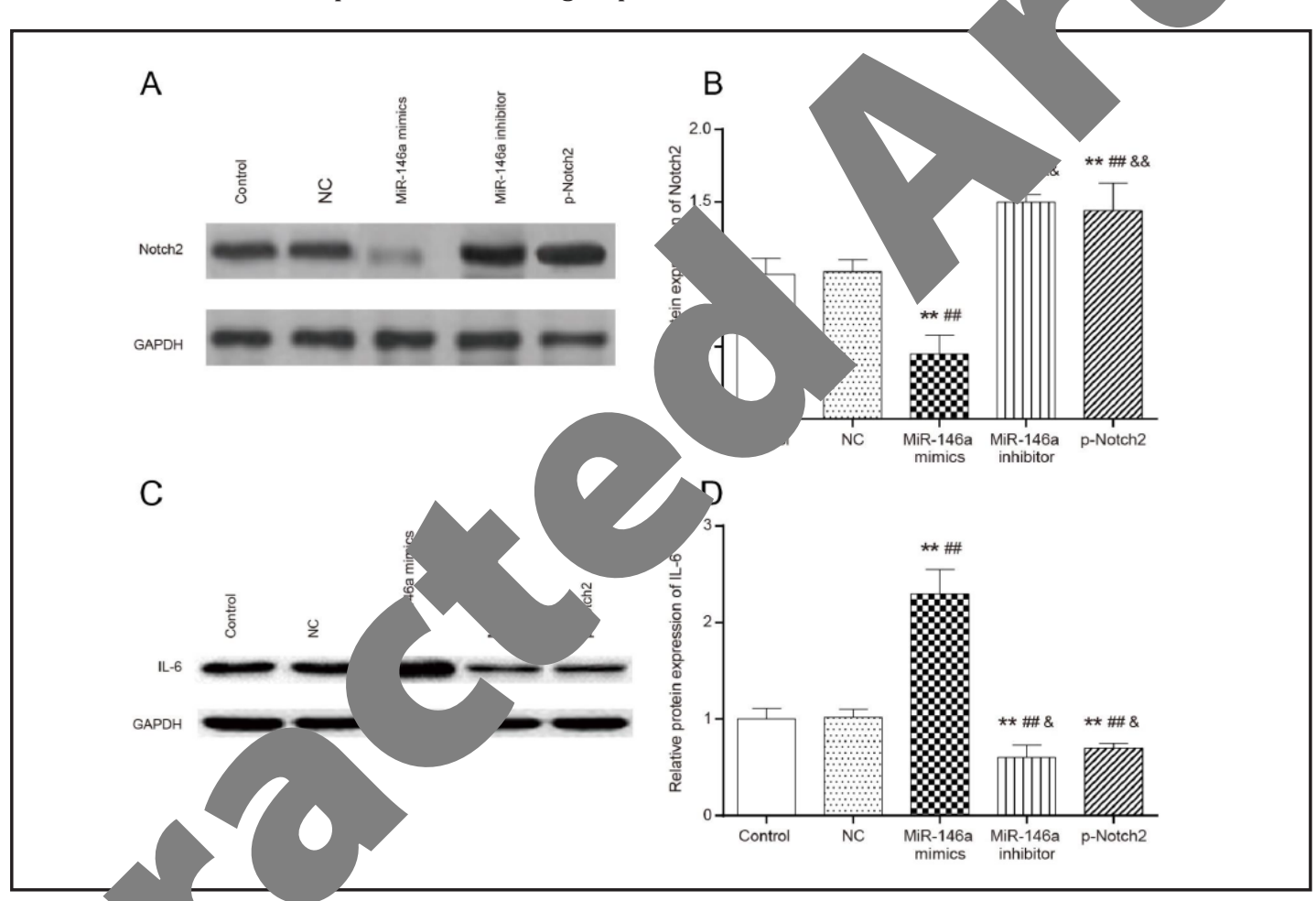

F 7 . De n2 pro OFs. (B) The column diagram of the expression level of Notch2 protein in OFs. Data were $\mathrm{d}$ as $\mathrm{m} \omega \mathrm{n} \pm \mathrm{SD} .{ }^{* *}, P<0.01$ compared with control group; \#\#, $P<0.01$ compared with the NC group; hpared with the miR-146a mimics group. (C) The expression level of IL-6 protein in OFs. (D)

column diagram of the expression level of IL-6 protein in OFs. Data were presented as mean $\pm \mathrm{SD}$. ${ }^{* *}, P<$ .07 mpared with control group; \#\#, $P<0.01$ compared with the NC group; ${ }^{\&}, P<0.05$, ${ }^{\& \&}, P<0.01$ compared the miR-146a mimics group. Control represented control group (OFs received no treatment), miR-146a mics represented miR-146a mimics group (OFs transfected with miR-146a mimics sequence), miR-146a inhibitors represented miR-146a inhibitor group (OFs transfected with miR-146a inhibitor sequence), NC represented negative control group (OFs transfected with miR-146a negative control duplex) group and p-Notch2 represented p-Notch2 group (OFs transfected with pcDNA3.1-Notch2). OFs: Orbital fibroblasts.

The effects of different groups on Notch2 and IL-6 expressions in OFs

To assess the effects of different groups on Notch2 and IL- 6 expressions in OFs, we examined the protein expressions of Notch2 and IL- 6 by western blot and ELISA. Western 
blot and ELISA results showed that $24 \mathrm{~h}$ after the transfection of miRNA-146a mimics in OFs, Notch2 was down-regulated whereas IL-6 was up-regulated compared with the control and NC groups $(P<0.01$, Fig. 6). Notch2 expressions in miR-146a inhibitor and p-Notch2 groups were significantly higher than that in the control and NC groups $(P<0.01)$ (Fig. 6A and 6B), IL-6 expressions in the miR-146a inhibitor and p-Notch2 groups were significantly low than that in the control and NC groups $(P<0.05$, Fig. 6C and 6D). Comparing with miR-146 mimics group, the expression of Notch2 significantly increased whereas the expression of IL-6 dramatically decreased $(P<0.05)$ in the p-Notch2 and the miR-146a inhibitor grour

\section{Discussion}

GO, especially active GO, has long been a major challenge for the en Active GO has more propensity to Th1 cells immune response, while has more propensity to Th2 cells immune response [4]. We investigate microRNA-146a/Notch2 signaling pathway regulating IL-6 in GO.

We compared the expression of miR-146a and Noto active vactive GO and normal orbital connective tissue. The expression of m not y increased in GO tissues compared with that in normal tissues, and m 46 sion in the active GO tissues significantly exceeded the inactive tissues, while spowion level of Notch2 showed the opposite trend. In addition, we ind ed that mik sa markedly promoted the GO Orbital Fibroblasts' (OFs') viability and mitu 'ut marked suppressed cell apoptosis, while Notch2 showed the opposite effects.

The effect of microRNAs in autoimmu dis has been attracting increasing interest of numerous researchers. Because $s$ an ammatory autoimmune disease, miR-146a seems to be up-regulated by tress as in GO. Similarly, there have several researchers reported that mir to pression was increased in diseased tissue of autoimmune diseases. For example, increased in rheumatoid art miR-146a expression was in et in carcllage of low-grade osteoarthritis [26]. Sonkoly

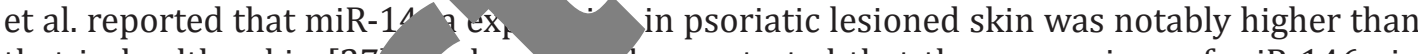
that in healthy skin [27 auley e. demonstrated that the expressions of miR-146a in peripheral blood mono with healthy controls [L markedly decre Bernecker et that miR-146a was significantly decreased in the thyroid tissue
of Graves ease GD 00 . Intriguingly, Wei et al. indicated that the miR-146a expression o0]. Intriguingly, Wei et al. indicated that the miR-146a expression in plas $r$ GD not notably different from that of the control group, and the $r$ iR $-140 \quad$ ression in GO patients was not only significantly reduced but also negatively ated the clinical activity of GO [3]. The distinction in the expression of miR-146a zutoin mune diseases may be accounted for the complex mechanisms of the different diseases.

Most recently, miR-146a has been found to negatively regulate cytokines [31]. According ratures, miR-146a had the following targets, including IGF1R, COX-2, TRAF6, FAS, 4, IRAK1, CCND1, MMP16, and COL4A3 [32-35]. Similar to the findings of Liu et al. and o et al., our study showed that Notch2 can be directly targeted by microRNA-146a [36, 37]. The Notch signaling pathway is an evolutionarily conserved pathway participated in cell proliferation, differentiation, and apoptosis [38]. Notch2, a major member of Notch family, was found to have a negative role on the activities of glioma cell and vascular smooth muscle cell. Xu et al. suggested that increase of Notch2 induced cell apoptosis, but inhibited cell growth and invasion, similarly to the results of interfering Notch1 [39]. In addition, Boulay et al. indicated that high levels of Notch2 were a serviceable prognosis in all subtypes of glioma [40]. Liu et al. indicated that Notch1 and Notch2 were directly inhibited by miR146a in glioma cells, and maintained a balance in regulating cell behavior and the altered

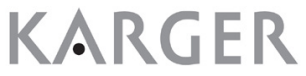




\section{Cellular Physiology Cell Physiol Biochem 2017;41:1285-1297

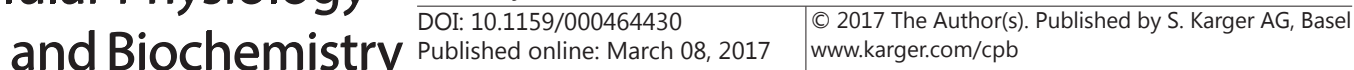

6 Cawood TJ, Moriarty P, O'Farrelly C, O'Shea D: The effects of tumour necrosis factor-alpha and interleukin1 on an in vitro model of thyroid-associated ophthalmopathy; contrasting effects on adipogenesis. Eur J Endocrinol 2006;155:395-403.

7 Niyazoglu M, Baykara O, Koc A, Aydogdu P, Onaran I, Dellal FD, Tasan E, Sultuybek GK: Association of PARP-1, NF-kappaB, NF-kappaBIA and IL-6, IL-1beta and TNF-alpha with Graves Disease and Graves Ophthalmopathy. Gene 2014;547:226-232.

-8 Pedersen I, David M: MicroRNAs in the immune response. Cytokine 2008;43:391-394.

-9 Abou-Zeid A, Saad M, Soliman E: MicroRNA 146a expression in rheumatoid arthritis: association with tumor necrosis factor-alpha and disease activity. Genet Test Mol Biomarkers 2011;15:807-812.

10 Wang H, Peng W, Ouyang X, Li W, Dai Y: Circulating microRNAs as candidate biomarkers in systemic lupus erythematosus. Transl Res 2012;160:198-206.

Pov S, Schwab S, Derfuss T: Getate deregulated microRNA expression in relapsing remitting multiple sclerosis. PLoS One inflammation and proliferation in Graves' ophthalmopathy. Med Sci Monit 2014.20

-13 Zhang F, Wang J, Chu J, Yang C, Xiao H, Zhao C, Sun Z, Gao X, Chen G, Han Z, Zou Induced by Hypoxia Promotes Chondrocyte Autophagy through $\mathrm{Bc}$ 1453.

14 Sharma AR, Sharma G, Lee SS, Chakraborty C: miRNA-Regulated K Pathways and Inflammation in Rheumatoid Arthritis. Med Res Rev 2
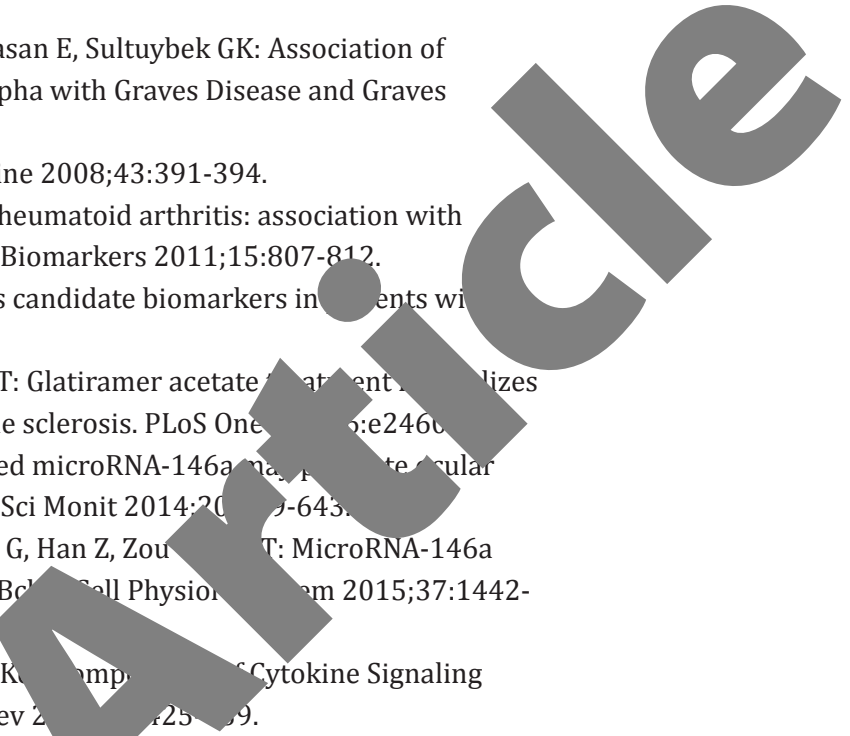
Jang SY, Chae MK, Lee JH, Lee EJ, Yoon JS: Role of mi ${ }^{P} \quad 6 a$ in the Regu Model of Graves' Orbitopathy. Invest Ophthalmol Vis 16;57:4027Xu D, Han Q, Hou Z, Zhang C, Zhang J: miR-146a negatiw Cell Mol Immunol DOI:10.1038/cmi.2015.113.

17 He Y, Sun X, Huang C, Long XR, Lin X, Zhang L, Lv X lipopolysaccharide-induced RAW264.7 mac 82.

18 Huang C, Liu XJ, QunZhou, Xie J Ma TT, I inhibiting Notch1 pathway in

19 Nakano N, Nishiyama C, Yagita confers antigen-presentin IInu. mast cells. J Allergy Clin Immunol 2009;123:74-81.e71.

-20 Zhang Q, Wang C, Liu Z, , Han C, Li N: Notch signal suppresses Toll-like receptor-triggered inflammatory response nacror'hages by inhibiting extracellular signal-regulated kinase 1/2-mediated nuclear factor kannaB ac ol Chem 2012;287:6208-6217.

-21 Feldon SE, Pa ughim orv, Nguyen VT, Landskroner-Eiger S, Chang D, Thatcher TH, Phipps RP: Autologous stimulate proliferation of orbital fibroblasts derived from patients with Graves' ophtho opath ve ohthalmol Vis Sci 2005;46:3913-3921.

-22 Sem Ki GD, it J, Smith TJ, Phipps RP: Human orbital fibroblasts are activated through CD40 to ind. inflammatory cytokine production. Am J Physiol 1998;274:C707-714.

ahlbe berling HJ, Joba W, Schworm HD, Heufelder AE: Detection and modulation of interleukin-1 eptor a. gonist messenger ribonucleic acid and immunoreactivity in Graves' orbital fibroblasts. Invest ol Vis Sci 1997;38:1018-1028.

Spltzweg C, Joba W, Hunt N, Heufelder AE: Analysis of human thyrotropin receptor gene expression and immunoreactivity in human orbital tissue. Eur J Endocrinol 1997;136:599-607.

Nakasa T, Miyaki S, Okubo A, Hashimoto M, Nishida K, Ochi M, Asahara H: Expression of microRNA-146 in rheumatoid arthritis synovial tissue. Arthritis Rheum 2008;58:1284-1292.

Yamasaki K, Nakasa T, Miyaki S, Ishikawa M, Deie M, Adachi N, Yasunaga Y, Asahara H, Ochi M: Expression of MicroRNA-146a in osteoarthritis cartilage. Arthritis Rheum 2009;60:1035-1041.

27 Sonkoly E, Wei T, Janson PC, Saaf A, Lundeberg L, Tengvall-Linder M, Norstedt G, Alenius H, Homey B, Scheynius A, Stahle M, Pivarcsi A: MicroRNAs: novel regulators involved in the pathogenesis of psoriasis? PLoS One 2007;2:e610.

-28 Pauley KM, Satoh M, Chan AL, Bubb MR, Reeves WH, Chan EK: Upregulated miR-146a expression in peripheral blood mononuclear cells from rheumatoid arthritis patients. Arthritis Res Ther 2008;10:R101. 


\section{Cellular Physiology Cell Physiol Biochem 2017;41:1285-1297

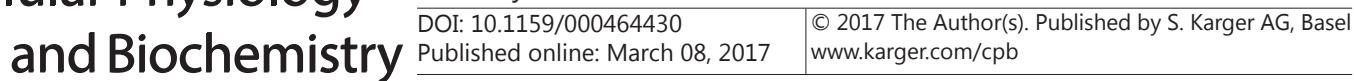 \\ Wang/Chen/Long: MicroRNA-146a Regulates IL-6 in Graves Ophthalmopathy via Notch2}

29 Wang G, Tam LS, Li EK, Kwan BC, Chow KM, Luk CC, Li PK, Szeto CC: Serum and urinary cell-free MiR-146a and MiR-155 in patients with systemic lupus erythematosus. J Rheumatol 2010;37:2516-2522.

-30 Bernecker C, Lenz L, Ostapczuk MS, Schinner S, Willenberg H, Ehlers M, Vordenbaumen S, Feldkamp J, Schott M: MicroRNAs miR-146a1, miR-155_2, and miR-200a1 are regulated in autoimmune thyroid diseases. Thyroid 2012;22:1294-1295.

-31 Boldin MP, Taganov KD, Rao DS, Yang L, Zhao JL, Kalwani M, Garcia-Flores Y, Luong M, Devrekanli A, Xu J, Sun G, Tay J, Linsley PS, Baltimore D: miR-146a is a significant brake on autoimmunity, myeloproliferation, and cancer in mice. J Exp Med 2011;208:1189-1201.

-32 Iyer S, Bahn R: Immunopathogenesis of Graves' ophthalmopathy: the role of the TSH receptor Best Pr Res Clin Endocrinol Metab 2012;26:281-289.

33 van Steensel L, Dik WA: The orbital fibroblast: a key player and target for therapy in graves' ophthalmopathy. Orbit 2010;29:202-206.

34 Ammari M, Jorgensen C, Apparailly F: Impact of microRNAs on the understanding ana rheumatoid arthritis. Curr Opin Rheumatol 2013;25:225-233.

-35 Liu H, Chen M, Wu F, Li F, Yin T, Cheng H, Li W, Liu B, Wang Q, Tao L: rs2910164 Pol a Decreased Risk for Pulmonary Hypertension by Compromising the Processir Physiol Biochem 2015;36:1951-1960.

-36 Liu R, Li W, Wu C: A functional polymorphism in the premiR146。 glioblastoma multiforme by interfering with the balance between 2015;12:5475-5481.

37 Cao J, Zhang K, Zheng J, Dong R: MicroRNA-146a an proliferation via modulation of the Notch signaling $\mathrm{P} \quad$ Mol Med R $\quad$ 15;11:2889-2895. cooperate to ate vascular smooth muscle cell

38 Bray SJ: Notch signalling: a simple pathway becomes $c$

39 Xu P, Zhang A, Jiang R, Qiu M, Kang C, Jia Z, Wang G Notch2 in astrocytic gliomas. PLoS One 2013;8:e5: Boulay JL, Miserez AR, Zweifel C, Sivasanka Wasner M, Van Meir E, Tolnay M, Reifent tr rlo A. LOSS of NOTCH2 positively predicts survival in subgroups of human glial brain tumors.

41 Raychaudhuri N, Douglas RS, 1 L-6 in orbital fibroblasts through EP2 receptors and increased gene promoter implicanons to thyroid-associated ophthalmopathy. PLoS One 2010;5:e15296.

42 Hiromatsu Y, Yang D, Be and orbital fat tissue fro thents arith thyroid-associated ophthalmopathy J Clin Endocrinol Metab 2000;85:1194-1199.

43 Deon D, Ahm Scarıu N, Herrero C, Lee IH, Krause A, Ivashkiv LB: Cross-talk between IL-1 and IL-6 signali roumatoid arthritis synovial fibroblasts. J Immunol 2001;167:5395-5403.

44 Molnar Balaz Hir wculating IL-6 level in Graves' ophthalmopathy. Autoimmunity 1997;25:91-96. 